\title{
Does adding water to dry calf starter improve performance during summer?
}

\author{
H. Beiranvand, ${ }^{* 1}$ M. Khani,† S. Omidian, ${ }^{*}$ M. Ariana,ł R. Rezvani, $§$ and M. H. Ghaffari† \\ ${ }^{*}$ FKA Agri-Animal Production Co., Isfahan, 13895-81799, Iran \\ †Department of Animal Science, College of Agriculture, Isfahan University of Technology, Isfahan, 84156-83111, Iran \\ ¥Department of Animal Science, Khorramabad Branch, Islamic Azad University, Khorramabad, 68178-16645, Iran \\ $\S$ Department of Animal Science, Saveh Branch, Islamic Azad University, Saveh, Iran
}

\begin{abstract}
The objective of this study was to determine whether addition of water to starter would improve performance, rumen fermentation parameters, blood metabolites, and behavior in dairy calves. For this purpose, 30 Holstein male calves ( $3 \mathrm{~d}$ of age; $42.0 \pm 4.2 \mathrm{~kg}$ of body weight) were randomly assigned to 1 of the following 3 starter diets differing in moisture content: (1) 90\% dry matter (DM), (2) 75\% DM, and (3) 50\% DM. Weaning and final body weight values were found to increase linearly with increasing dietary water. Moreover, starter intake increased linearly during the preweaning and overall periods. Average daily gain also increased linearly in calves receiving the $75 \%$ and $50 \%$ DM diets compared with those receiving the $90 \%$ DM diet. However, treatments had no effects on gain-to-feed ratio. Adding water to a starter with $50 \%$ DM led to linear increases in both total volatile fatty acids and molar proportions of acetate and propionate in the rumen but it had no effect on the molar proportions of butyrate, isovalerate, or valerate, nor did it have any effect on acetate-to-propionate ratio. Similarly, times spent on eating, ruminating, standing, lying, and nonnutritive oral behavior exhibited no differences across treatments. Finally, addition of water to the starter diet led to no significant changes in the concentrations of selected blood metabolites, respiration rate, or rectal temperature. Results indicate that calves readily accept wetter feeds with a DM content of $50 \%$ and that adding water to starter diets improves calf performance during the hot months of summer.
\end{abstract}

Key words: moisture level, performance, dairy calf

\section{INTRODUCTION}

During heat stress periods, dairy calves exhibit poor growth and higher susceptibility to diseases due

Received June 23, 2015.

Accepted November 8, 2015.

${ }^{1}$ Corresponding author: hamedbeiran669@gmail.com to reduced feed intake (West, 2003) and increased maintenance energy needs coupled with lowered immunity (Tao and Dahl, 2013). Previous studies have shown significantly decreased ADG in calves during the summer months (Place et al., 1998; Bateman and Hill, 2012). Studies have shown that consumption of solid feed in starter diets can contribute to optimized development of the rumen in calves, thereby leading to greater potential for early weaning (Coverdale et al., 2004; Beiranvand et al., 2014). Adding water to a TMR is often suggested as a method to improve feed palatability and reduce preferential feed sorting (Leonardi et al., 2005); however, no study has reported the effects of adding water to starter diets on the performance and behavior of dairy calves. Increased moisture content has been reported to reduce dust associated with feeding a TMR (Arzola-Álvarez et al., 2010), and to increase palatability as a result of improved texture or dilution of undesirable flavors (Lahr et al., 1983). Traditionally, adding water to a dry TMR has been considered a beneficial management practice to decrease the degree of feed sorting (Shaver, 2002). Leonardi et al. (2005) demonstrated that adding water to TMR (reducing the DM content from 81 to $64 \%$ ) diminished feed sorting against longer particles by adult cows. Moreover, Miller-Cushon and DeVries (2009) reported that adding water to reduce DM concentration in a TMR from 57.6 to $47.9 \%$ decreased DMI, and Khan et al. (2014) maintained that a DM less than $65 \%$ tended to decrease DMI in dairy heifers $(175 \pm 12 \mathrm{~d}$ of age). Other studies have, however, reported increases in DMI as DM content in the diet of dairy cattle (e.g., Lahret al., 1983). From a different aspect, TMR with higher moisture levels are thought to be more susceptible to spoilage in hot and humid conditions (Eastridge, 2006), and feed consumption will be reduced if feed is spoiled or not fresh.

The present study was designed to determine the effects of adding water to a starter on feed intake, ADG, feed efficiency, rumen fermentation parameters, blood metabolites, and nutritional behavior of dairy calves during the hot months of summer. Our hypothesis was 
that adding water to a dry starter will enhance ration adhesiveness, making it harder for calves to sort out smaller particles, which, in turn, will lead to increased solid feed consumption and improved calf performance.

\section{MATERIALS AND METHODS}

\section{Calves, Treatments, and Management}

The study was conducted from June 22 to September 22, 2014, at the FKA Agri-Animal Production Co. (Isfahan, Iran). Calves were cared for according to the guidelines of the Iranian Council of Animal Care (1995). Air temperature and relative humidity data were obtained from the daily reports released by the Meteorological Network Station at Najaf-Abad (Isfahan, Iran). The temperature-humidity index (THI) was calculated using the following equation (García-Ispierto et al., 2006):

$$
\begin{aligned}
\mathrm{THI}= & 0.8 \times \text { maximum } \mathrm{T}+(\text { minimum } \mathrm{RH} / 100) \\
& \times(\text { maximum } \mathrm{T}-14.4)+46.4,
\end{aligned}
$$

where $\mathrm{T}$ is air temperature $\left({ }^{\circ} \mathrm{C}\right)$ and $\mathrm{RH}$ is relative humidity (\%).

Thirty Holstein male calves ( $3 \mathrm{~d}$ of age; $42.0 \pm 4.2$ $\mathrm{kg}$ of $\mathrm{BW}$ ) were separated from their dams immediately after birth, weighed, and randomly transferred to individual pens $(1.5 \times 2.5 \mathrm{~m})$. The pens were cleaned every $3 \mathrm{~d}$ by removing all bedding and replacing it with fresh sawdust bedding. All calves were fed 3 to $4 \mathrm{~L}$ of colostrum within 2 to $6 \mathrm{~h}$ after birth. The animals were fed starter diets with identical ingredients and nutrient compositions but differing in moisture content: (1) $90 \%$ DM (dry diet), (2) 75\% DM (wet diet), and (3) $50 \%$ DM (wetter diet). Calves were fed pasteurized waste milk containing $3.40 \pm 0.11 \%$ fat, $2.70 \pm 0.07 \% \mathrm{CP}$, and $4.92 \pm 0.05 \%$ lactose at an approximate rate of $10 \%$ of their initial BW (4 kg/animal per day) in steel buckets twice daily at 0800 and $1600 \mathrm{~h}$ until weaning. Before milk feeding, the milk was warmed in a water bath to raise its temperature to $38 \pm 0.5^{\circ} \mathrm{C}$. The calves were provided ad libitum access to water and starter throughout the study period to permit at least $10 \%$ orts (i.e., the portion of the starter not consumed over a 24 -h period). Starter feed refusal from each individual calf was collected at $0800 \mathrm{~h}$. The animals were weaned on d 50 and the study was terminated on d 70 .

Basal diet was formulated to meet NRC (2001) requirements for calf nutrients. The ingredients and nutrient composition of the basal diet are shown in Table 1. The health criteria of the calves were monitored using the procedure described in Heinrichs et al. (2003), and calves with mild scours were treated according to the standard operating procedure of the farm (Beiranvand et al., 2014).

\section{Data Collection and Sampling}

To calculate feed intake, the offered and refused amounts of starter were recorded daily on an individual basis. All the calves were weighed at birth and subsequently every $10 \mathrm{~d}$ until the end of the experimental period (d 70). Gain-to-feed ratio (feed efficiency $=\mathrm{kg}$ of BW gain $/ \mathrm{kg}$ of total DMI) was also calculated. In addition, heart girth and hip width measurements were made on $\mathrm{d} 3$, at weaning (d 50), and at the end of the study period (d 70).

On d 70 of the study, rumen samples were collected with a stomach tube approximately $3 \mathrm{~h}$ after the morning feeding and strained through 4 layers of cheesecloth to obtain rumen fluid. Ruminal $\mathrm{pH}$ was immediately measured using a mobile $\mathrm{pH}$ meter (HI 8314 membrane pH meter, Hanna Instruments, Villafranca, Italy). Ten milliliters of rumen fluid was acidified with $2 \mathrm{~mL}$ of $25 \%$ meta-phosphoric acid, placed on ice, and transferred to the laboratory where the sample was stored $\left(-20^{\circ} \mathrm{C}\right)$ until analysis for VFA.

Table 1. Ingredients and chemical composition (\% of DM unless otherwise noted) of the basal diet

\begin{tabular}{lc}
\hline Composition & \% of DM \\
\hline Ingredient & \\
Chopped alfalfa hay & 10 \\
Barley grain ground & 20 \\
Barley grain rolled & 10 \\
Whole corn grain & 21.9 \\
Soybean meal, $45 \% \mathrm{CP}$ & 30.1 \\
Corn gluten meal & 5 \\
Calcium carbonate & 0.9 \\
Dicalcium phosphate & 0.6 \\
Salt & 0.5 \\
Sodium bicarbonate & 0.5 \\
Vitamin and mineral mix ${ }^{1}$ & 0.5 \\
Nutrient composition & \\
ME, ${ }^{2}$ Mcal/kg & 3.03 \\
NE ${ }_{\mathrm{G}}{ }^{\text {Mcal } / \mathrm{kg}}$ & 1.73 \\
DM & 90 \\
CP & 22.7 \\
NDF & 16.4 \\
ADF & 8.4 \\
Lipid & 2.8 \\
Ash & 8.0 \\
Ca & P $^{2}$
\end{tabular}

${ }^{1}$ Contained per kilogram of supplement: 250,000 IU of vitamin A, $50,000 \mathrm{IU}$ of vitamin D, 1,500 IU of vitamin E, $2.25 \mathrm{~g}$ of Mn, $120 \mathrm{~g}$ of $\mathrm{Ca}, 7.7 \mathrm{~g}$ of $\mathrm{Zn}, 20 \mathrm{~g}$ of P, $20.5 \mathrm{~g}$ of $\mathrm{Mg}, 186 \mathrm{~g}$ of Na, $1.25 \mathrm{~g}$ of Fe, $3 \mathrm{~g}$ of S, $14 \mathrm{mg}$ of Co, $1.25 \mathrm{~g}$ of Cu, $56 \mathrm{mg}$ of I, and $10 \mathrm{mg}$ of Se.

${ }^{2}$ Calculated from NRC (2001). 
Blood samples were collected $3 \mathrm{~h}$ after the morning feed on d 3, 15, 35, 45, 60, and 70 of the study period. Another blood sample was collected at $1400 \mathrm{~h}$ to measure blood glucose levels at the peak temperature of the day. Blood was withdrawn from the jugular vein of each calf into evacuated tubes ( $7 \mathrm{~mL}$ per sample) containing EDTA as an anticoagulant and placed immediately on ice. Tubes were centrifuged at 2,000 $\times g$ for $20 \mathrm{~min}$ at $4^{\circ} \mathrm{C}$ to separate the plasma, which was then stored at $-20^{\circ} \mathrm{C}$ for subsequent analysis.

Respiration rate (RR) was measured at $1500 \mathrm{~h}$ on d 30,45 , and 70 , by visual observation for three 1-min periods (not consecutive) according to the methods described by Yari et al. (2010). Immediately after recording RR, rectal temperature (RT) was recorded using a thermometer (Qingdao Dacon Trading Co. Ltd., Shandong, China). Behavioral data (eating, ruminating, standing, lying, and nonnutritive oral behavior) were monitored by direct observations of all the calves over the total time (min) devoted to each monitored behavior once per week before weaning (d 35 of the experiment) and on $\mathrm{d} 70$ of the study. Calves were observed $8 \mathrm{~h}$ after the morning milk feeding (at $0800 \mathrm{~h}$ ) during the preweaning week. During the postweaning week, they were observed $8 \mathrm{~h}$ after the solid feed had been offered at $0800 \mathrm{~h}$. Thus, the total time for each calf behavior was equal to $16 \mathrm{~h}$ (consisting of $8 \mathrm{~h}$ before and $8 \mathrm{~h}$ after weaning).

\section{Laboratory Analyses}

Feed and refusals were mixed thoroughly and ground to pass a 1-mm screen in a Wiley mill (Ogaw Seiki Co., Ltd., Tokyo, Japan) before samples were chemically analyzed for their DM content (method 934.01; AOAC, 1990) and CP (method 988.05; AOAC, 1990). Neutral detergent fiber was analyzed without the use of sodium sulfite but with $\alpha$-amylase included (Van Soest et al., 1991). Milk samples were analyzed for fat, CP, lactose, and TS contents using the Milkoscan (Foss Electric, Hillerød, Denmark; AOAC International, 1997).

Rumen samples were analyzed for VFA by gas chromatography (model CP-9002, Chrompack, Middelburg, the Netherlands) with a 50-m (0.32 mm internal diameter) fused-silica column (CP-Wax Chrompack Capillary Column, Varian, Palo Alto, CA). Helium was used as the carrier gas, and oven initial and final temperatures were set to 55 and $195^{\circ} \mathrm{C}$, respectively. Detector and injector temperatures were set at $250^{\circ} \mathrm{C}$. Crotonic acid $(1: 7, \mathrm{vol} / \mathrm{vol})$ was used as the internal standard.

Blood metabolite concentrations were determined using commercially available kits [Pars Azmoon Company, Tehran, Iran; cat. no. glucose (1-500-017), and urea nitrogen (BUN; 1-400-029)] using an autoanalyzer (Technicon RA 1000, Bayer, Tarrytown, NY) according to the manufacturer's instructions. Blood concentrations of $\mathrm{BHB}$ were determined by enzymatic analysis

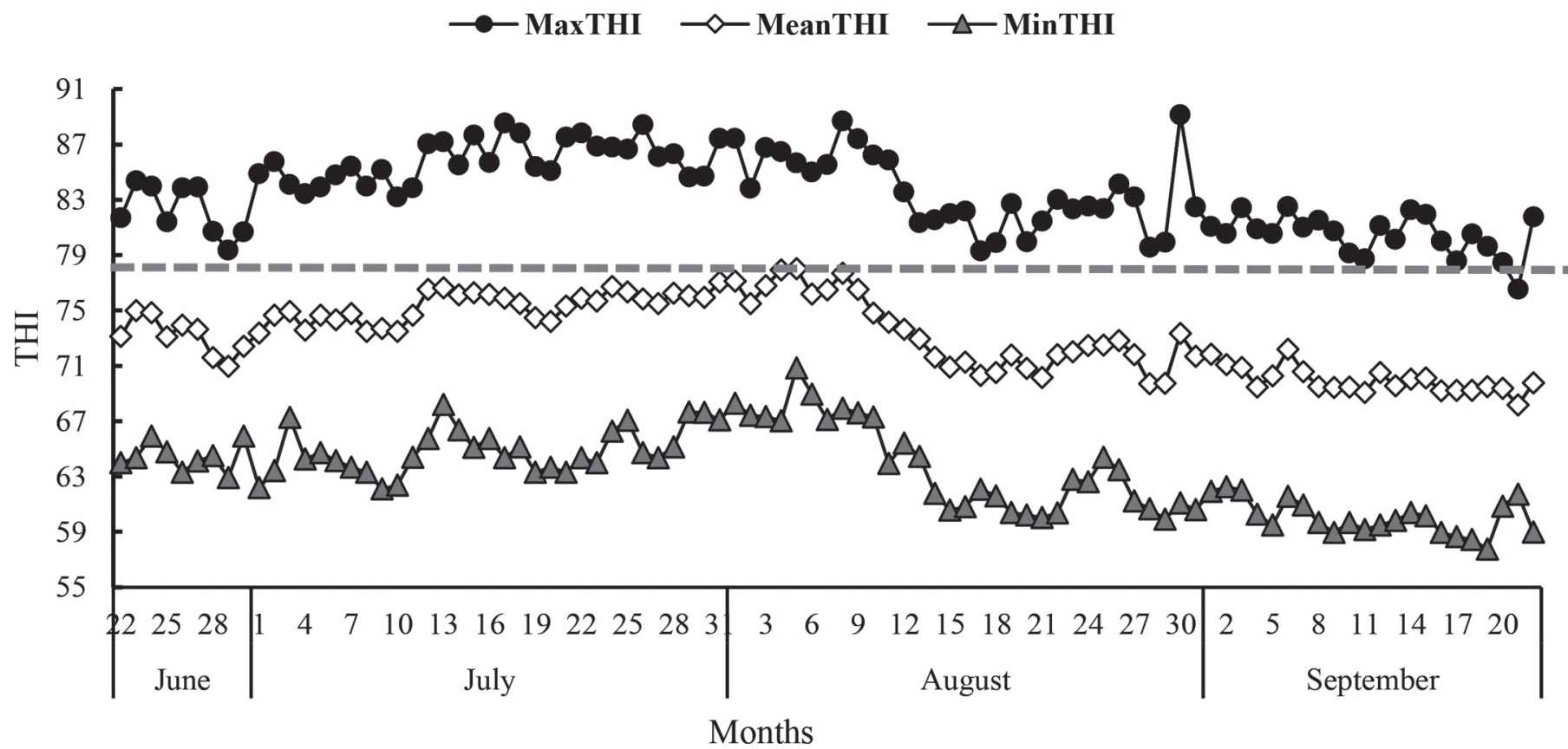

Figure 1. Mean, minimum (Min), and maximum (Max) daily temperature-humidity indices (THI) during the study period. Dashed lines represent THI $\geq 78$. 
(BHBA dehydrogenase; DRG Co., Marburg, Germany; Iwersen et al., 2009).

\section{Statistical Analyses}

Data on starter intake, ADG, feed efficiency, and blood metabolites (glucose and BHB) were analyzed using a repeated-measures mixed model (PROC MIXED) of SAS (SAS Institute, 2002), including calf as the random component of the model and diet (dry, wet, and wetter), age (week), and their interaction as fixed components. Data on ruminal fermentation characteristics on d 70 were analyzed as a completely randomized design with dietary treatments used as the main factor. Initial weight was included in the model as a covariates for weaning and final weights. The lowest
Bayesian information criterion (fit statistic) level was used to select the covariance structure, and the autoregression structure was accordingly modeled. Orthogonal polynomial contrasts were used to determine linear and quadratic effects with control by increasing levels of moisture in all measurements of sows and piglets. When differences were detected in treatments or interactions, means separation analysis was conducted using a Tukey adjustment for $P$. Significance was declared at $P \leq 0.05$.

\section{RESULTS AND DISCUSSION}

\section{Climatic Conditions}

Average daily minimum, mean, and maximum THI values are shown in Figure 1. The average maximum

Table 2. Effects of dietary treatments on BW, starter intake, ADG, gain-to-feed ratio, heart girth, and hip width ( $\mathrm{n}=10$ per treatment)

\begin{tabular}{|c|c|c|c|c|c|c|c|}
\hline \multirow[b]{2}{*}{ Item } & \multicolumn{3}{|c|}{ Treatment $^{1}$} & \multirow[b]{2}{*}{ SEM } & \multicolumn{3}{|c|}{$P$-value ${ }^{2}$} \\
\hline & Dry & Wet & Wetter & & TRT & $\mathrm{L}$ & $\mathrm{Q}$ \\
\hline \multicolumn{8}{|l|}{$\mathrm{BW}, \mathrm{kg}$} \\
\hline Initial, d 1 & 41.38 & 42.20 & 42.20 & 0.59 & 0.52 & 0.43 & 0.76 \\
\hline At weaning, d 50 & $66.61^{\mathrm{b}}$ & $70.82^{\mathrm{ab}}$ & $73.24^{\mathrm{a}}$ & 1.54 & 0.02 & 0.01 & 0.63 \\
\hline Final, d 70 & 87.00 & 92.70 & 94.94 & 2.42 & 0.08 & 0.03 & 0.55 \\
\hline \multicolumn{8}{|l|}{ Starter intake, kg } \\
\hline Preweaning & $0.55^{\mathrm{b}}$ & $0.77^{\mathrm{ab}}$ & $0.83^{\mathrm{a}}$ & 0.07 & 0.05 & 0.02 & 0.41 \\
\hline d 3 to 10 & $0.02^{\mathrm{b}}$ & $0.11^{\mathrm{a}}$ & $0.12^{\mathrm{a}}$ & 0.01 & $<0.001$ & $<0.001$ & 0.01 \\
\hline d 11 to 20 & $0.15^{\mathrm{b}}$ & $0.39^{\mathrm{a}}$ & $0.47^{\mathrm{a}}$ & 0.03 & $<0.001$ & $<0.001$ & 0.05 \\
\hline d 21 to 30 & $0.42^{\mathrm{b}}$ & $0.74^{\mathrm{a}}$ & $0.76^{\mathrm{a}}$ & 0.05 & $<0.001$ & $<0.001$ & 0.03 \\
\hline d 31 to 40 & $0.68^{\mathrm{b}}$ & $0.99^{\mathrm{a}}$ & $1.21^{\mathrm{a}}$ & 0.07 & $<0.001$ & $<0.001$ & 0.61 \\
\hline d 41 to 50 & 1.55 & 1.70 & 1.72 & 0.14 & 0.66 & 0.32 & 0.72 \\
\hline Postweaning & 2.19 & 2.46 & 2.53 & 0.12 & 0.17 & 0.07 & 0.54 \\
\hline d 51 to 60 & 2.16 & 2.48 & 2.56 & 0.13 & 0.10 & 0.04 & 0.47 \\
\hline d 60 to 70 & 2.22 & 2.44 & 2.62 & 0.14 & 0.19 & 0.07 & 0.91 \\
\hline Overall & $1.03^{\mathrm{b}}$ & $1.26^{\mathrm{ab}}$ & $1.31^{\mathrm{a}}$ & 0.07 & 0.04 & 0.01 & 0.38 \\
\hline \multicolumn{8}{|l|}{$\mathrm{ADG}, \mathrm{g}$} \\
\hline Preweaning & $0.5^{\mathrm{b}}$ & $0.64^{\mathrm{a}}$ & $0.67^{\mathrm{a}}$ & 0.02 & $<0.01$ & $<0.01$ & 0.17 \\
\hline d 3 to 10 & 0.19 & 0.33 & 0.30 & 0.05 & 0.12 & 0.10 & 0.21 \\
\hline d 11 to 20 & $0.28^{\mathrm{b}}$ & $0.49^{\mathrm{a}}$ & $0.55^{\mathrm{a}}$ & 0.05 & $<0.01$ & $<0.01$ & 0.35 \\
\hline d 21 to 30 & 0.58 & 0.72 & 0.67 & 0.06 & 0.29 & 0.32 & 0.22 \\
\hline d 31 to 40 & $0.54^{\mathrm{b}}$ & $0.71^{\mathrm{a}}$ & $0.79^{\mathrm{a}}$ & 0.03 & $<0.01$ & $<0.01$ & 0.36 \\
\hline d 41 to 50 & 0.89 & 0.91 & 1.04 & 0.07 & 0.33 & 0.18 & 0.55 \\
\hline Postweaning & 1.06 & 1.11 & 1.07 & 0.07 & 0.88 & 0.92 & 0.64 \\
\hline d 51 to 60 & 1.07 & 1.19 & 1.07 & 0.07 & 0.47 & 0.99 & 0.22 \\
\hline d 60 to 70 & 1.04 & 1.03 & 1.09 & 0.12 & 0.95 & 0.81 & 0.84 \\
\hline Overall & $0.66^{\mathrm{b}}$ & $0.77^{\mathrm{a}}$ & $0.79^{\mathrm{a}}$ & 0.03 & 0.01 & $<0.01$ & 0.19 \\
\hline \multicolumn{8}{|l|}{ Gain-to-feed ratio ${ }^{3}$} \\
\hline Preweaning & 0.48 & 0.52 & 0.50 & 0.02 & 0.48 & 0.58 & 0.28 \\
\hline Postweaning & 0.39 & 0.37 & 0.33 & 0.02 & 0.37 & 0.16 & 0.77 \\
\hline Overall & 0.45 & 0.48 & 0.45 & 0.01 & 0.52 & 0.98 & 0.26 \\
\hline \multicolumn{8}{|l|}{ Heart girth, cm } \\
\hline Weaning & 89.19 & 89.87 & 88.96 & 0.83 & 0.76 & 0.85 & 0.48 \\
\hline Final & 99.83 & 101.42 & 100.75 & 0.97 & 0.53 & 0.53 & 0.34 \\
\hline \multicolumn{8}{|l|}{ Hip width, cm } \\
\hline Weaning & 14.28 & 14.40 & 14.11 & 0.16 & 0.49 & 0.48 & 0.33 \\
\hline Final & 17.15 & 17.46 & 17.32 & 0.25 & 0.69 & 0.63 & 0.48 \\
\hline
\end{tabular}

${ }^{\mathrm{a}, \mathrm{b}}$ Means within a row with different superscripts are significantly different $(P<0.05)$.

${ }^{1}$ Treatment: dry = basal dry diet without water added; wet = basal dry diet plus $25 \%$ water added (DM basis); wetter $=$ basal dry diet plus $50 \%$ water added (DM basis).

${ }^{2} \mathrm{TRT}=$ treatment effect, $\mathrm{L}=$ linear effect, $\mathrm{Q}=$ quadratic effect.

${ }^{3}$ Gain-to-feed ratio was calculated by dividing ADG (g) by average daily DMI; values are means of the different periods pre- and postweaning. 


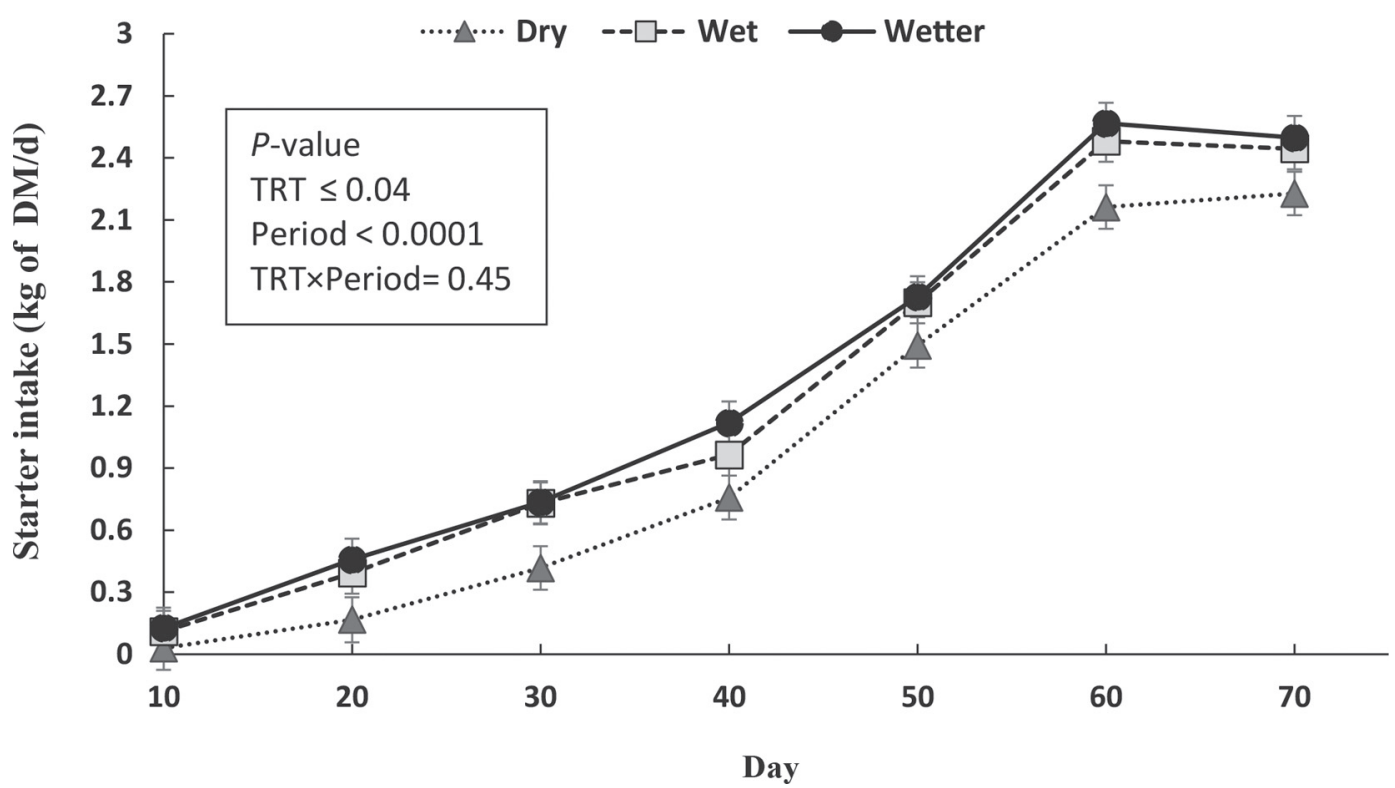

Figure 2. Average starter intake in calves fed different diets. Dry = basal diet with $90 \%$ DM $(\mathbf{\Delta})$, wet $=$ basal diet with $75 \%$ DM $(\boldsymbol{\square})$, wetter $=$ basal diet with $50 \%$ DM $(\bullet)$. TRT = treatment. Error bars represent impact values for each mean.

THI during the study period was 86 , indicating a high degree of heat stress. In central Iran, THI can reach 83 from May through September (Yari et al., 2010). For the purposes of this study, THI values of 78 to 79 and those $\geq 83$ were considered as moderate and severe degrees of stress, respectively, for dairy calves (Coleman et al., 1996).
Compared with dairy cows, calves may be more able to cope with warmer temperatures due to their large surface area relative to BW and much lower heat generation. For cows, signs of heat stress appear when THI exceeds 72 and become pronounced at a THI of 76 or above (Johnson, 1987). The stated thresholds for heat stress apply for calves, which may also tolerate higher

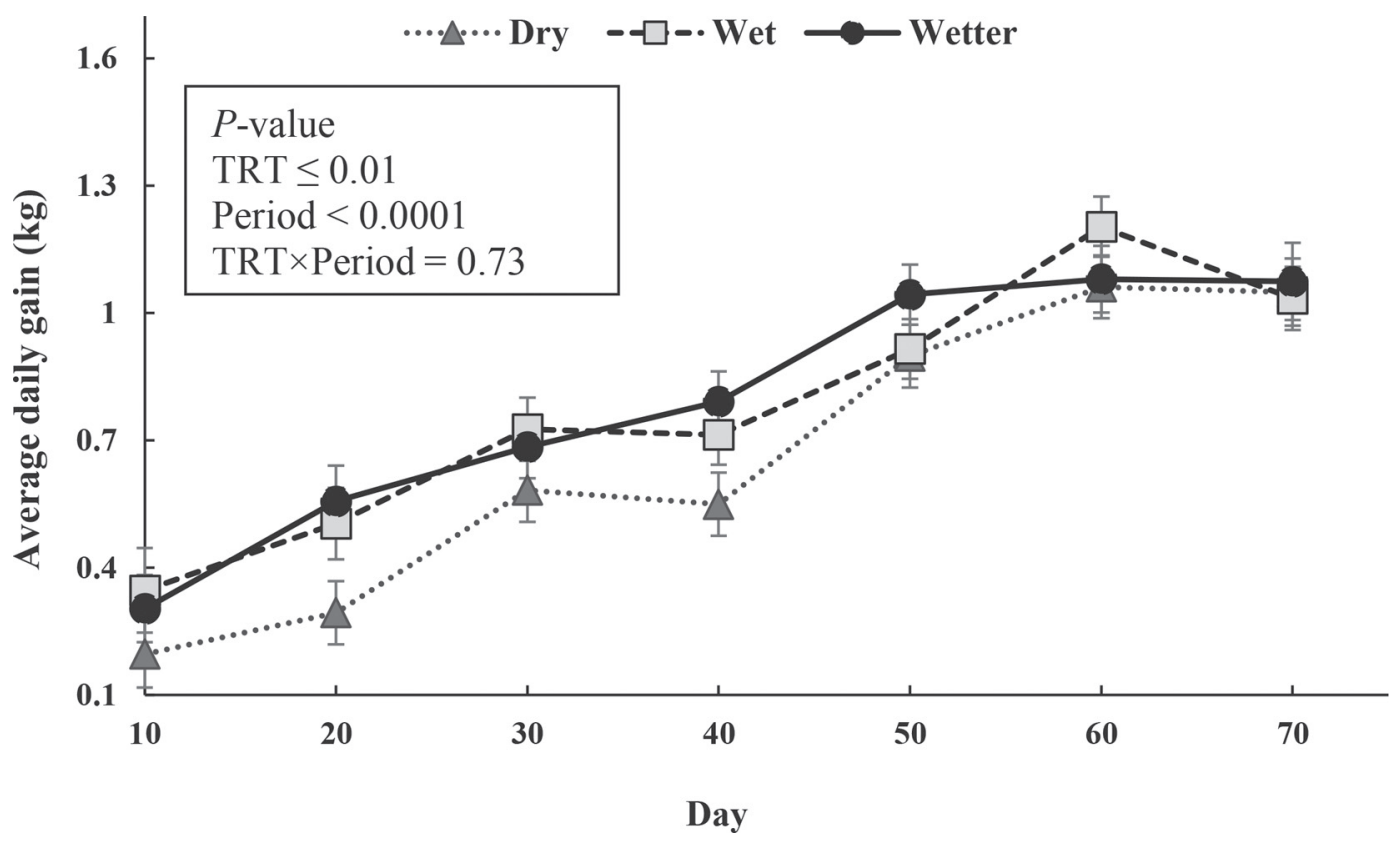

Figure 3. Average daily gain in calves fed different diets. Dry = basal diet with $90 \%$ DM $(\mathbf{\Lambda})$, wet $=$ basal diet with $75 \%$ DM $(\mathbf{\square})$, wetter $=$ basal diet with $50 \%$ DM $(\bullet)$. TRT = treatment. Error bars represent impact values for each mean. 
Table 3. Effects of dietary treatments on rumen fermentation parameters $(n=10$ per treatment)

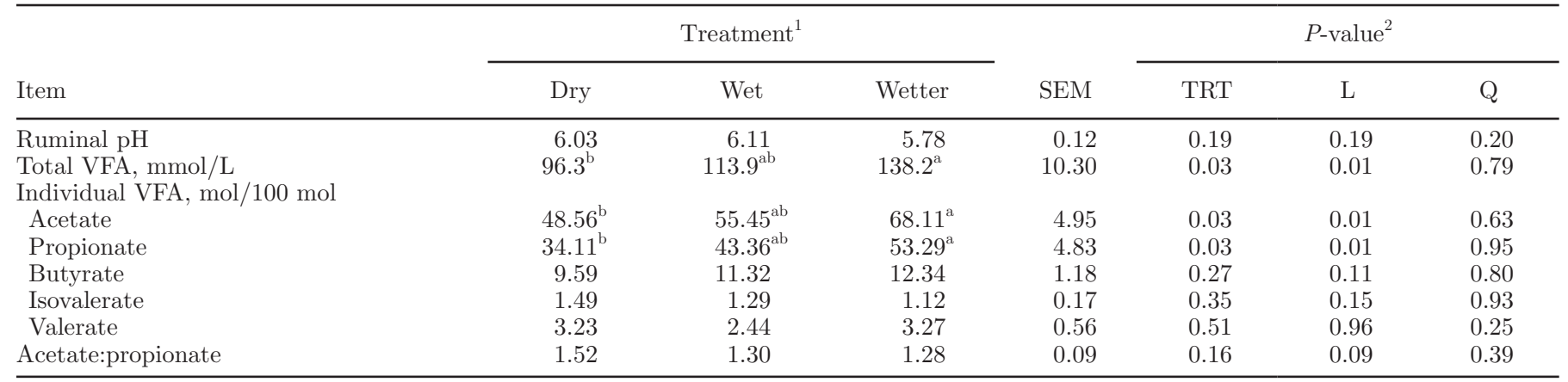

${ }^{\mathrm{a}, \mathrm{b}}$ Means within a row with different superscripts letters are significantly different $(P<0.05)$.

${ }^{1}$ Treatments: dry = basal dry diet without water added; wet = basal dry diet plus $25 \%$ water added (DM basis); wetter $=$ basal dry diet plus $50 \%$ water added (DM basis).

${ }^{2} \mathrm{TRT}=$ treatment effect, $\mathrm{L}=$ linear effect, $\mathrm{Q}=$ quadratic effect.

THI. More recent data on calf responses to heat stress in a controlled environment are not available.

\section{Starter Intake and Growth Performance}

All calves remained healthy and exhibited no signs of illness during the experiment. The data for BW, starter intake, ADG, gain:feed ratio, heart girth, and hip width are presented in Table 2. Weaning BW ( $P$ $<0.05)$ and final BW $(P<0.01)$ linearly increased as a result of adding water to the diet. Starter intake increased (linearly, $P<0.01$ ) with increasing dietary moisture content during the preweaning and overall periods. Starter intake from d 3 to 40 of the study increased (linearly, $P<0.01$ ) with water addition (Figure
2 ). In support of our hypothesis, the increased starter intake in calves fed the wet and wetter diets might have been due to the greater palatability of the starter with increased moisture, so that calves were encouraged to consume more feed during the early weeks of life (d 3 to 40). Felton and DeVries (2010) suggested that greater amounts of water added to a TMR would result in greater increases in feed temperature during the hours after feed is placed in the feed bunk, particularly at higher ambient temperatures. This increase in feed temperature may be indicative of spoilage, which may contribute to reduce DMI, as also reported by MillerCushon and DeVries (2009). In the current study, no molding or spoilage was observed in the feed during the summer months, probably because fresh starter was

Table 4. Total times devoted to perform different behaviors during $8 \mathrm{~h}$ of observation in pre- and postweaning periods ${ }^{1}$

\begin{tabular}{|c|c|c|c|c|c|c|c|}
\hline \multirow[b]{2}{*}{ Item } & \multicolumn{3}{|c|}{ Treatment $^{2}$} & \multirow[b]{2}{*}{ SEM } & \multicolumn{3}{|c|}{$P$-value ${ }^{3}$} \\
\hline & Dry & Wet & Wetter & & TRT & $\mathrm{L}$ & Q \\
\hline \multicolumn{8}{|l|}{ Eating, min } \\
\hline Preweaning & 36.42 & 30.00 & 34.16 & 4.32 & 0.54 & 0.72 & 0.30 \\
\hline Postweaning & 74.28 & 55.00 & 65.00 & 5.66 & 0.08 & 0.25 & 0.05 \\
\hline \multicolumn{8}{|c|}{ Ruminating, min } \\
\hline Preweaning & 110.71 & 92.77 & 92.50 & 7.44 & 0.16 & 0.11 & 0.32 \\
\hline Postweaning & 78.57 & 65.71 & 60.00 & 10.74 & 0.46 & 0.23 & 0.79 \\
\hline \multicolumn{8}{|l|}{ Standing, min } \\
\hline Preweaning & 135.7 & 124.4 & 134.2 & 8.86 & 0.59 & 0.90 & 0.32 \\
\hline Postweaning & 100.0 & 115.0 & 120.6 & 9.43 & 0.30 & 0.13 & 0.69 \\
\hline \multicolumn{8}{|l|}{ Lying, min } \\
\hline Preweaning & 185.0 & 217.8 & 207.5 & 11.82 & 0.14 & 0.21 & 0.13 \\
\hline Postweaning & 207.1 & 232.1 & 220.0 & 12.17 & 0.38 & 0.45 & 0.23 \\
\hline \multicolumn{8}{|c|}{ Nonnutritive oral behavior, ${ }^{4} \min$} \\
\hline Preweaning & 12.14 & 15.00 & 11.66 & 3.39 & 0.73 & 0.92 & 0.44 \\
\hline Postweaning & 20.00 & 12.14 & 14.37 & 5.02 & 0.54 & 0.43 & 0.42 \\
\hline
\end{tabular}

${ }^{1}$ Periods: preweaning $=35 \mathrm{~d}$ of age; postweaning $=70 \mathrm{~d}$ of age.

${ }^{2}$ Treatments: dry = basal dry diet without water added; wet = basal dry diet plus $25 \%$ water added (DM basis); wetter $=$ basal dry diet plus $50 \%$ water added (DM basis).

${ }^{3} \mathrm{TRT}=$ treatment effect, $\mathrm{L}=$ linear effect, $\mathrm{Q}=$ quadratic effect.

${ }^{4}$ Tongue rolling, licking surfaces, or eating wood shavings. 
prepared and provided each day. Khan et al. (2014) tested how the moisture content of the TMR affected feed intake and feed sorting by heifers, which was not in line with our findings. The differences observed in the results might be attributed to differences in feed composition (e.g., forage source and levels, forage-toconcentrate ratio, and feed particle size), environmental conditions (e.g., temperature and humidity), moisture levels, and different animal age groups (calf vs. heifer; Khan et al., 2014).

Average daily gain was greater (linear, $P<0.01$ ) during the preweaning and overall periods in calves fed the wet and wetter diets compared with those fed the dry diets but was not affected by treatment during the postweaning period (Figure 3). However, treatment had no effect on gain-to-feed ratio in any period. The higher ADG values obtained during the preweaning stage and throughout the experimental period in calves fed wet and wetter diets might be attributed to the greater solid feed intake by the animal and improved uniformity and adhesiveness and lower dustiness of the moist starter. Heart girth and hip width did not differ among the treatments. To our knowledge, this experiment is the first to report on the effect of starter moistening on the structural growth of dairy calves.

\section{Rumen Fermentation Parameters}

The data for rumen fermentation parameters are presented in Table 3 . Ruminal $\mathrm{pH}$ remained unaffected by addition of water to the diet. The total ruminal VFA concentration and the molar proportions of acetate and propionate linearly increased $(P<0.01)$ with increasing dietary water. The molar proportions of butyrate, isovalerate, and valerate, and the acetate-to-propionate ratio were similar across dietary treatments. We are not aware of any study in which rumen fermentation of calves have been compared with respect to the effects of ad libitum feeding of dry or wet diets. However, where comparisons have been made, similar results have been reported for ruminal $\mathrm{pH}$ (Lahr et al., 1983). Leonardi et al. (2005) reported that reducing TMR DM concentration from 80 to $64 \%$ by water addition had no effect on ruminal $\mathrm{pH}$ or $\mathrm{NH}_{3}-\mathrm{N}$ and VFA concentrations in dairy cattle. In the present study, adding water to starter was found to help bind feed particles together and thereby enhance the consumption of a more consistent ration that provided more nutrients to stimulate ruminal fermentation in young calves. Similar to these findings, Lahr et al. (1983) observed that cows fed a 78\% DM diet had higher propionate concentrations in the rumen than those fed a $52 \%$ DM diet, whereas the molar proportions of valerate and isovalerate were higher in the latter cows than in those receiving other diets.

\section{Animal Behavior}

The total times devoted to different behaviors are presented in Table 4. No differences were found among treatments in times spent eating, ruminating, standing, lying, or nonnutritive oral behavior. Eating time decreased quadratically $(P<0.05)$ during the postweaning period in calves receiving wet diets compared with those receiving either the dry or wetter diets. To the
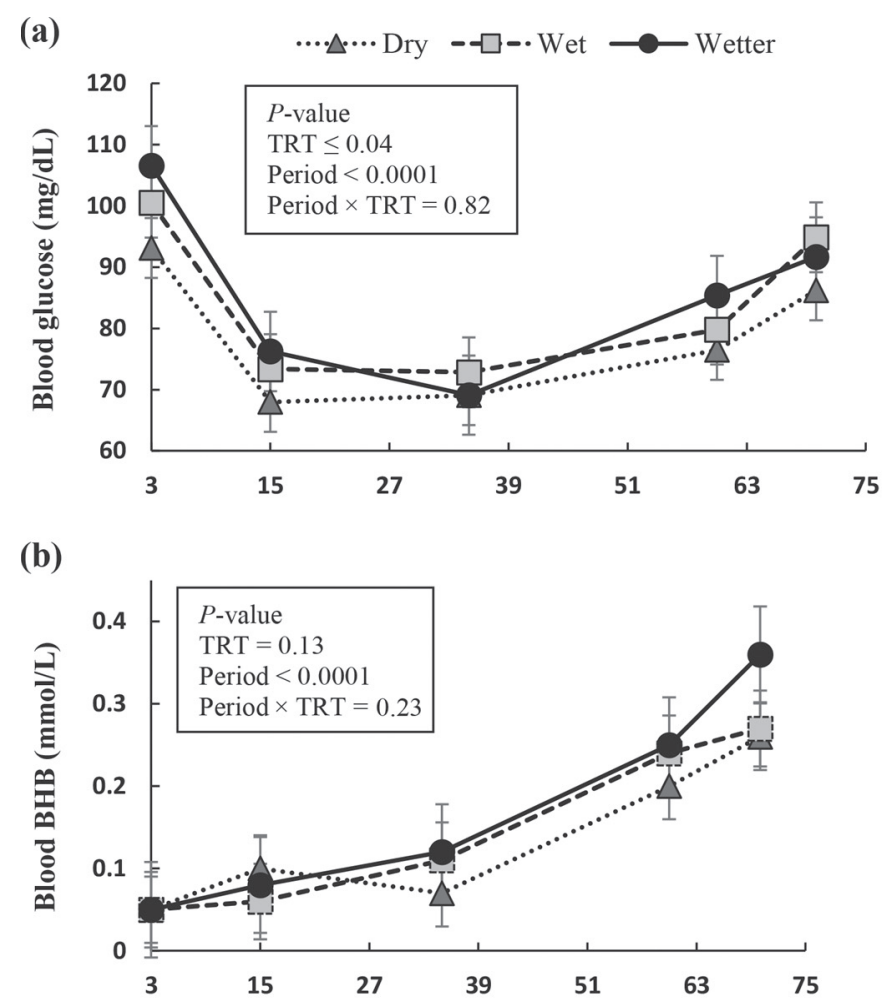

(c)

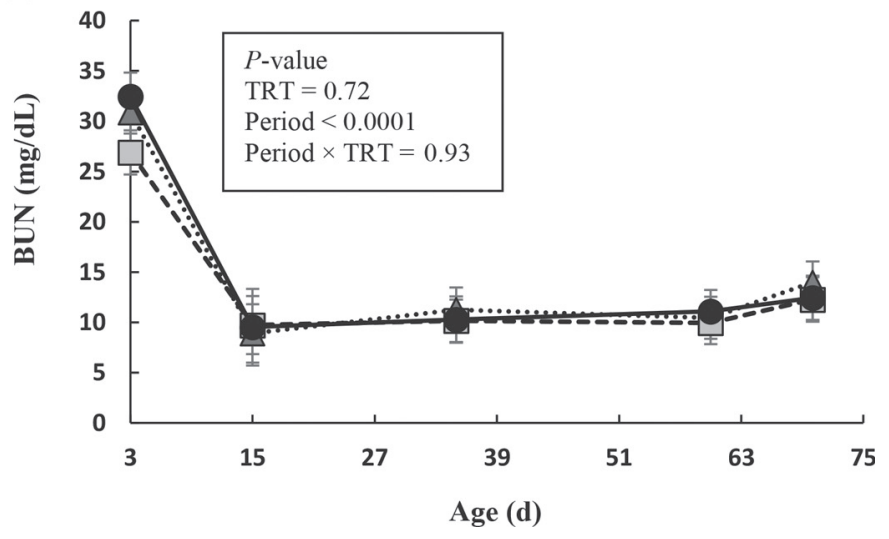

Figure 4. Mean $( \pm$ SE) blood glucose (a), BHB (b), and BUN (c) concentrations of calves. Blood samples (d 3, 15, 35, 60, and 70) were taken from the jugular vein. Values are shown separately for Holstein calves receiving different starter diets. Dry = basal diet with $90 \% \mathrm{DM}$ (ム), wet = basal diet with $75 \% \mathrm{DM}(\mathbf{\square})$, wetter = basal diet with $50 \%$ $\mathrm{DM}(\bullet)$. TRT $=$ treatment. 
Table 5. Effect of dietary treatments ${ }^{1}$ (means \pm SE) on blood glucose, respiratory rate, and rectal temperature at the peak heat of the day (n $=10$ per treatment)

\begin{tabular}{|c|c|c|c|c|c|c|}
\hline \multirow[b]{2}{*}{ Item and treatment } & \multicolumn{3}{|c|}{ Age of calves ${ }^{2}(\mathrm{~d})$} & \multicolumn{3}{|c|}{$P$-value ${ }^{3}$} \\
\hline & 30 & 45 & 70 & TRT & $\mathrm{L}$ & $\mathrm{Q}$ \\
\hline Dry & $67.59 \pm 3.40$ & $69.33 \pm 3.58$ & $76.37 \pm 3.40$ & & & \\
\hline Wet & $77.16 \pm 3.58$ & $66.88 \pm 3.24$ & $80.66 \pm 3.58$ & & & \\
\hline Wetter & $75.26 \pm 3.58$ & $71.44 \pm 3.58$ & $79.71 \pm 3.40$ & & & \\
\hline Respiration rate, breaths/min & & & & 0.09 & 0.07 & 0.19 \\
\hline Wetter & $48.34 \pm 3.51$ & $44.20 \pm 3.33$ & $60.00 \pm 3.33$ & & & \\
\hline Rectal temperature, ${ }^{\circ} \mathrm{C}$ & & & & 0.72 & 0.84 & 0.44 \\
\hline Dry & $39.02 \pm 0.10$ & $39.03 \pm 0.10$ & $39.29 \pm 0.10$ & & & \\
\hline Wet & $38.79 \pm 0.10$ & $39.04 \pm 0.10$ & $39.28 \pm 0.10$ & & & \\
\hline Wetter & $39.00 \pm 0.10$ & $39.06 \pm 0.10$ & $39.22 \pm 0.10$ & & & \\
\hline
\end{tabular}

${ }^{1}$ Treatment: dry = basal dry diet without water added; wet = basal dry diet plus $25 \%$ water added (DM basis); wetter = basal dry diet plus $50 \%$ water added (DM basis).

${ }^{2}$ Periods: preweaning $=\mathrm{d} 30$ and 45 of age; postweaning $=\mathrm{d} 70$ of age.

${ }^{3} \mathrm{TRT}=$ treatment effect, $\mathrm{L}=$ linear effect, $\mathrm{Q}=$ quadratic effect; treatment $\times$ time interactions were not significant.

best of our knowledge, animal behavior has not been concurrently measured in experiments where dietary treatments consisted of different moisture contents. Sorting activity was not measured in the current study but this is recommended for future studies. Khan et al. (2014) reported that sorting activity of heifers was not affected by the moisture content of the TMR.

\section{Blood Metabolites, $R R$, and $R T$}

The data for blood metabolites are presented in Figure 4. No differences were observed among treatments in blood glucose, BHB, or BUN. The data for blood glucose at the peak temperature of the day, RR, and RT are presented in Table 5. Given the scant information reported in the literature on the effects of adding water to starter on blood metabolites and, in particular, on the RR and RT of dairy calves, the findings of the current study showed that addition of water to starter (up to $50 \% \mathrm{DM}$ ) had no significant effects on blood glucose concentration, RT, and RR of young calves on d 30,45 , and 70 .

\section{CONCLUSIONS}

Addition of water to starter increases intake, weaning BW, and ADG, especially during the first weeks of life. Adding water to the starter diet was also found to linearly increase total VFA and molar proportions of acetate and propionate in the rumen. However, it did not result in any changes in the concentration of blood metabolites, RT, or RR. Overall, these results suggest that the addition of water to starter diets (up to $50 \%$
DM) improves calf performance during the hot months of the summer.

\section{ACKNOWLEDGMENTS}

FKA Agri-Animal Production Co. (Isfahan, Iran) is acknowledged for their full funding of this study. Jamshid Jalilnejad (FKA Agri.-Animal Production Co.) is also appreciated for his assistance throughout the experiments. Amir Khamesi-Tehrani, Mahmod Motamedi, Alireza Shafiee, Alireza Mirzakhani, Farzan Sabzevari, Vahid Moharamdi, and Mohammad Mohammadi (all from FKA Agri.-Animal Production Co.) and Farzad Hashemzadeh-Cigari (from Isfahan University of Technology, IUT, Isfahan, Iran),also deserve our gratitude for their cooperation. The authors also express their appreciation to the farm veterinarians Hamid-Reza Sahabi, Mehdi Safahani-Langrodi, and Mohsen Khosravi-Bakhtiari for their relentless efforts. Finally, E. Roustazadeh from IUT is acknowledged for editing the final English manuscript.

\section{REFERENCES}

AOAC. 1990. Official Methods of Analysis. 15th ed. Association of Official Analytical Chemists, Arlington, VA.

AOAC International. 1997. Official Methods of Analysis. 16th ed. AOAC International, Gaithersburg, MD.

Arzola-Alvarez, C., J. A. Bocanegra-Viezca, M. R. Murphy, J. SalinasChavira, A. Corral-Luna, A. Romanos, O. Ruíz-Barrera, and C. Rodríguez-Muela. 2010. Particle size distribution and chemical composition of total mixed rations for dairy cattle: Water addition and feed sampling effects. J. Dairy Sci. 93:4180-4188.

Bateman, G. II, and M. Hill. 2012. How heat stress impacts the growth of calves. Prog. Dairyman 26:55-57.

Beiranvand, H., G. R. Ghorbani, M. Khorvash, A. Nabipour, M. Dehghan-Banadaky, A. Homayouni, and S. Kargar. 2014. Interactions 
of alfalfa hay and sodium propionate on dairy calf performance and rumen development. J. Dairy Sci. 97:2270-2280.

Coleman, D. A., B. R. Moss, and T. A. Mccaskey. 1996. Supplemental shade for dairy calves reared in commercial calf hutches in a southern climate. J. Dairy Sci. 79:2038-2043.

Coverdale, J. A., H. D. Tyler, J. D. Quigley III, and J. A. Brumm. 2004. Effect of various levels of forage and form of diet on rumen development and growth in calves. J. Dairy Sci. 87:2554-2562.

Eastridge, M. L. 2006. Major advances in applied dairy cattle nutrition. J. Dairy Sci. 89:1311-1323.

Felton, C. A., and T. J. DeVries. 2010. Effect of water addition to a total mixed ration on feed temperature, feed intake, sorting behavior, and milk production of dairy cows. J. Dairy Sci. 93:2651-2660.

García-Ispierto, I., F. López-Gatius, P. Santolaria, J. L. Yániz, C. Nogareda, M. López-Béjar, and F. De Rensis. 2006. Relationship between heat stress during the peri-implantation period and early fetal loss in dairy cattle. Theriogenology 65:799-807.

Heinrichs, A. J., C. M. Jones, L. R. VanRoekel, and M. A. Fowler 2003. CalfTrack: A system of dairy calf workforce management training, and evaluation and health evaluation. J. Dairy Sci. 86(Suppl. 1):115 (Abstr.).

Iranian Council of Animal Care. 1995. Guide to the Care and Use of Experimental Animals. Vol. 1. Isfahan University of Technology, Isfahan, Iran.

Iwersen, M., U. Falkenberg, R. Voigtsberger, D. Forderung, and W. Heuwieser. 2009. Evaluation of an electronic cowside test to detect subclinical ketosis in dairy cows. J. Dairy Sci. 92:2618-2624.

Johnson, H. D. 1987. Bioclimate effects on growth, reproduction and milk production. Pages 35-57 in Bioclimatology and the Adaptation of Livestock. H. D. Johnson, ed. Elsevier, Amsterdam, the Netherlands.

Khan, M. A., A. Bach, L. Castells, D. M. Weary, and M. A. von Keyserlingk. 2014. Effects of particle size and moisture levels in mixed rations on the feeding behavior of dairy heifers. Animal $8: 1722-1727$

Lahr, D. A., D. E. Otterby, D. G. Johnson, J. G. Linn, and R. G. Lundquist. 1983. Effects of moisture content of complete diets on feed intake and milk production by cows. J. Dairy Sci. 66:1891-1900.

Leonardi, C., F. Giannico, and L. E. Armentano. 2005. Effect of water addition on selective consumption (sorting) of dry diets by dairy cattle. J. Dairy Sci. 88:1043-1049.

Miller-Cushon, E. K., and T. J. DeVries. 2009. Effect of dietary dry matter concentration on the sorting behavior of lactating dairy cows fed a total mixed ration. J. Dairy Sci. 92:3292-3298.

NRC. 2001. Nutrient Requirements of Dairy Cattle. 7th rev. ed. National Academic Press, Washington, DC.

Place, N. T., A. J. Heinrichs, and H. N. Erb. 1998. The effects of disease, management, and nutrition on average daily gain of dairy heifers from birth to four months. J. Dairy Sci. 81:1004-1009.

SAS Institute. 2002. SAS User's Guide: Statistics. Release 9.1. SAS Institute Inc., Cary, NC.

Shaver, R. D. 2002. Rumen acidosis in dairy cattle: Bunk management considerations. Adv. Dairy Tech. 14:241-249.

Tao, S., and G. E. Dahl. 2013. Invited review: Heat stress effects during late gestation on dry cows and their calves. J. Dairy Sci. 96:4079-1093.

Van Soest, P. J., J. B. Robertson, and B. A. Lewis. 1991. Methods for dietary fiber, neutral detergent fiber nonstarch polysaccharide in relation to animal nutrition. J. Dairy Sci. 74:3583-3597.

West, J. W. 2003. Effects of heat-stress on production in dairy cattle. J. Dairy Sci. 86:2131-2144.

Yari, M., A. Nikkhah, M. Alikhani, M. Khorvash, H. Rahmani, and G. R. Ghorbani. 2010. Physiological calf responses to increased chromium supply in summer. J. Dairy Sci. 93:4111-4120. 